\title{
Investigating Trends and Costs Associated with Designing Concrete Mixes Using Different Methods by Computer Programs
}

\author{
Mohammed Abdul Qader (D), ${ }^{1}$ Ahmed Ibrahim (D), Al-Badr Alaidaros $(\mathrm{D}){ }^{1}$ \\ Abdul Kareem Abdulkareem $\left(\mathbb{D},{ }^{1}\right.$ Abdullah Alwuayl $\left(\mathbb{D},{ }^{1}\right.$ Abdullah Alsaluli $\left(\mathbb{D},{ }^{1}\right.$ \\ Mamdooh Alwetaishi $\left(\mathbb{D},{ }^{1}\right.$ Mishal Alsehli $\mathbb{D}^{2},{ }^{2}$ and Saleh Alghamdi $\mathbb{D}^{1}$ \\ ${ }^{1}$ Department of Civil Engineering, College of Engineering, Taif University, P.O. Box 11099, Taif 21944, Saudi Arabia \\ ${ }^{2}$ Department of Mechanical Engineering, College of Engineering, Taif University, P.O. Box 11099, Taif 21944, Saudi Arabia \\ Correspondence should be addressed to Saleh Alghamdi; sjalghamdi@tu.edu.sa
}

Received 12 October 2021; Accepted 4 January 2022; Published 6 February 2022

Academic Editor: Mehdi Nikoo

Copyright (C) 2022 Mohammed Abdul Qader et al. This is an open access article distributed under the Creative Commons Attribution License, which permits unrestricted use, distribution, and reproduction in any medium, provided the original work is properly cited.

\begin{abstract}
Concrete mixes can be designed using many methods such as the British method (DOE) and the American method (ACI). It is beneficial to compare different mixes and examine their performances and the associated costs. However, designing and comparing concrete mixes by hand can be time consuming and is prone to errors. Hence, in this work, algorithms were developed and implemented for six mix design methods, which replaced the time-consuming hand calculations with error-free and fast ones, in a user-friendly fashion. The programs successfully designed concrete mixes ranging from 10 to $160 \mathrm{MPa} 28$-day compressive strengths with minimal errors and provided estimates of the cost of each mix. Also, using the developed programs, methods were compared regarding their suggested concrete ingredients' quantities, associated cost, and general trends. Preliminary comparisons between mix design methods showed that design methods suggest similar mix proportions for a given compressive strength. Further, it was found that designing a mix using ACI method can be costly compared with the other methods. These findings and others would have been difficult to be revealed using traditional methods of mix design. More importantly, the comparisons presented in this work are only a few of the unlimited comparisons that can be easily made between normal and high strength mix design methods, which will unravel other key differences between mix design methods. Such comparisons are vital to engineers to be able to make informed decisions regarding which mix to use from strength, workability, durability, and cost point of views.
\end{abstract}

\section{Introduction}

There are numerous methods for designing concrete mixes, including the American Concrete Institute (ACI) method, the absolute volume method (AVM), and the Department of Environment (DOE) method. The objective of designing a concrete mix is to determine the amounts of concrete constituents. For normal strength concrete, the main constituents are cement, water, fine, and coarse aggregates. Chemical and/or mineral admixtures can be sometimes added to normal strength concrete mixes and are always added to high strength, high-performance concretes. Engineers usually perform concrete mix design calculations by hand, which can be prone to errors. In addition, comparing different mixes within the same method and mixes designed by different methods and evaluating the associated cost of each mix can be time consuming, much like other engineering design problems. However, ever since the advent of computers, solving engineering problems have become easier, faster, and in most cases more accurate [1]. In the field of concrete technology, researchers have used computers to design concrete mixes. For instance, Microsoft Excel has been used for designing concrete mixes as well as optimizing concrete mixes for cost efficiency and other variables [2, 3]. Nevertheless, performing calculations using Microsoft Excel can lead to errors as outlined by Teo and Tan in their research paper where they calculated the number of errors when MS Excel is used [4]. Similar findings were reported in 
[5-7]. Furthermore, most of the available Microsoft Excel sheets are unprotected and can be overwritten [1]. Besides MS Excel, standalone programs and MATLAB scripts have been used to design concrete mixes. For instance, Gupta, Mittal, and Saini developed a normal strength concrete mix designer using MATLAB. Further, researchers [8] created MATLAB programs to design high strength concrete mixes. Similarly, Makenya and John [1] reported a MATLAB program that is capable of designing concrete mixes of high strength using Erntroy and Shacklock method [9]. Abdullahi and Al-Mattarneh and Mohammed and Sadiku developed a MATLAB script to output the ingredients of light weight structural concrete [10]. Moreover, Wang Jizong Liang et al [11] used MATLAB to develop a mix optimization design for high-performance concrete.

In addition to using hard-coded programs to solve engineering problems, a substantial attention nowadays is directed to machine learning and deep learning techniques since they proved to be capable of solving complicated problems. Such techniques have been utilized to solve concrete mix design problems such as the prediction of concrete compressive strength. In 1998, Yeh [12] reported the efficacy of using artificial neural networks (ANNs) and linear regression in predicting the strength of high strength concrete. The use of ANN in predicting the strength of concrete continued as machine learning and deep learning methods improved, solving problems related to strength prediction of normal and high strength concrete [13-18], high strength and high-performance concrete [19-21] and ultra-high-performance concrete [22], recycled aggregate concrete [23], structural lightweight concrete [24], and selfconsolidating concrete [25]. Besides neural networks, decision trees have also been used to predict compressive strength of different types of concrete such as high strength and high-performance concrete [26, 27], FRP-confined concrete [28], as well as recycled aggregate concrete $[29,30]$.

Comparisons between ACI and DOE methods regarding their mix designs and associated cost have been investigated and reported in literatures [18, 31]. Santoso described concrete mix designs using British DOE and American ACI methods according to compressive strength and cost using local materials. They reported that, in general, the ACI method was more effective and efficient than the DOE method. Additionally, Ejiogu et al. compared the ACI 211-92 mix design proportioning method for normal concrete with the British DOE Mix design proportioning method and the Indian Standard mix design proportioning method-IS 10262-82 and found that samples made according to the ACI method and IS methods achieved the targeted mean compressive strength while the DOE method did not for varying grades of concrete. Researcher concluded that the ACI method was more cost effective than the IS method.

Despite these efforts, the existing mix design programs are usually based on one method only and do not compare different methods of concrete mix design, neither for normal strength nor high strength concrete. Additionally, most of the available software in the literature do not offer a graphical user interface for the process of input and output of the data, which can be problematic and may further complicate the process of concrete mix design. Additionally, while the use of machine learning and artificial intelligence models proved to be very effective in solving problems of varying nature and difficulty, they are associated with prediction/classification errors. Further, available comparisons between mix design methods are limited with regard to the studied range of strengths and parameters. Therefore, in this work, we created GUI-aided programs that design concrete mixes using three methods for normal strength concrete and three mix design methods for high strength concrete. Output of the programs was used to draw conclusions regarding the differences in concrete ingredients quantities, associated cost, and general trends of all methods. For normal strength concrete, the methods used in this work are the absolute volume method (AVM), the American Concrete Institute (ACI 211) method, and the Department of Environment (DOE). For high strength concrete, the American Concrete Institute for high strength concrete mix design (ACI 211.4R), the modified DOE method for high strength concrete mixes, and the Aitcin method were used.

\subsection{Popular Mix Design Methods for Normal Strength Concrete}

1.1.1. Absolute Volume Method (AVM). The absolute volume mix design method is used by engineers as a fast method for designing concrete mixes. It is a part of the ACI 211 [32] method, and it assumes that the absolute volume of concrete is the sum of the absolute volumes of its constituents. The method uses predefined ratios for fine/coarse aggregate and gives the designer the freedom of choosing the water/cement ratio based on the required compressive strength of the hardened concrete. The main considerations and factors involved in this method are presented in Table 1.

\subsubsection{American Concrete Institute (ACI 211) Method.} The ACI 211 [32] method for designing concrete mixes is widely used. It is developed by the American Concrete Institute. It was first published in 1944, and the last edition was published in 1991 which was then revised in 2002. The method provides many empirical tables that enable designers to determine concrete mix's ingredients. The method can be used to design concrete mixes having either rounded or angular aggregates, regular or light weight aggregates, and air-entrained or non-air-entrained mixes.

1.1.3. Department of Environment (DOE) Method. DOE is the United Kingdom's Department of Environment method [33] which is also known as the British Standard method. It was first published in 1975 and then revised in 1988. The method uses many empirical charts rather than tables and has the advantage of choosing the type of aggregates that are being used, i.e., crushed or uncrushed as well as providing designers with the option to choose from two types of cements. 
TABLE 1: Comparison of normal strength mix design methods regarding the main considerations and factors involved in each method.

\begin{tabular}{|c|c|c|c|}
\hline Key considerations & $\mathrm{AVM}$ & $\mathrm{ACI}$ & $\mathrm{DOE}$ \\
\hline Fresh concrete consistency & No & Yes & Yes \\
\hline Average required strength based on previous tests & No & Yes & Yes \\
\hline Air-entrainment & No & Yes & No \\
\hline Size of aggregates & No & Yes & Yes \\
\hline Crushed-uncrushed aggregates & No & No & Yes \\
\hline Rapid hardening portland cement & No & No & Yes \\
\hline Percentage of fines passing $600 \mu$ sieve & No & No & Yes \\
\hline
\end{tabular}

\subsection{Popular Mix Design Methods for High Strength Concrete.} In the last few decades, mega projects such as skyscrapers and bridges necessitated the need for high strength concrete (HSC). HSC can also be used in smaller structures to reduce the size of the structural members hence maximizing the utilization of floor areas. Adding admixtures to the main ingredients of concrete can increase the strength of concrete. Such admixtures include mineral admixtures such as fly ash (FA), silica fume (SF), ground granulated blast-furnace slag (GGBS), and chemical admixtures which include plasticizers and superplasticizers [34]. The design of high strength concrete is far more complex than a normal strength concrete mix as it requires judicious selection of mix quantities and admixtures [9]. Description of the three methods used in this work is given below.

1.2.1. ACI 211.4R-08 Method. ACI 211.4R-08, Guide for Selecting Proportions for High Strength Concrete Using Portland Cement and Other Cementitious Materials [35], is a detailed guide for designing high strength concrete using different types of the cementitious materials such as cement, fly ash, cement slag, and silica fume. The guide provides a procedure for the design of HSC. The main considerations and factors involved in this method are presented in Table 2.

1.2.2. Aïtcin Method. Aïtcin [36] introduced a method for designing a high strength/performance concrete based on the ACI 211-1. A mix design using this method follows many simple steps that result in final design values. This method takes into consideration many factors, including aggregate shape.

1.2.3. Modified DOE Method. Modified DOE [37] is based on the design of normal concrete mixes published by the Department of Environment (DOE) of United Kingdom. Experimental results showed that the concrete proportioned by this method can achieve a compressive strength of up to $120 \mathrm{MPa}$ at the age of 28 days [37].

\section{Methods}

2.1. Mix Design Computer Programs. The process of creating programs that replace manual calculations of a concrete mix design involves many steps starting from understanding the mix design method to converting empirical graphs and tables to computer-accessible format and finally
TABLE 2: Comparison of high strength mix design methods regarding the main considerations and factors involved in each method.

\begin{tabular}{lccc}
\hline Key considerations & ACI $211.4 \mathrm{R}-$ & Aïtcin & Modified \\
& 08 & & DOE \\
\hline Range & $47-83 \mathrm{MPa}$ & $40-160 \mathrm{MPa}$ & $60-100 \mathrm{MPa}$ \\
Superplasticizer & Yes & Yes & Yes \\
Cementitious & Yes & Yes & Yes \\
materials & No & Yes & No \\
Aggregate shape & & &
\end{tabular}

meticulously comparing results of the program to manual calculations. The following steps are followed in the implementation of all programs. These steps are presented in a block diagram in Figure 1.

Step 1. Understanding each mix design method. Prior to commencing the process of coding, authors spent sufficient time understanding each method and how it can be best programmed and presented to users.

Step 2. Setting up the coding environment. Authors decided to use MATLAB (MathWorks, Inc, MA, USA) coding environment because it provides tools for terminal coding as well as applications for the creation of graphical user interfaces. MATLAB Guide was used to create all GUI's. All programs were created and tested using MATLAB 2020a.

Step 3. Converting empirical tables to matrices. All tables of numerical values from each mix design method were loaded to the MATLAB program as matrices of rows $i$ and columns $j$. Hence, all values in the table can be accessed by providing the coordinates $i$ and $j$. Some tables, however, have only several values that have been extracted from experiments; hence, required values that lie in between of the existing values in the table can be interpolated. To illustrate this idea, consider the table that correlates $\mathrm{w} / \mathrm{c}$ ratio to compressive strength in the ACI method [32], shown in Figure 2. In this table, only a few values of $\mathrm{w} / \mathrm{c}$ ratio corresponding to concrete compressive strength are provided, and other values can be interpolated. For this case, data points in the table were fitted and replaced with a polynomial modal equation. This was performed using MATLAB fitting app, which can fit data points using a variety of functions such as polynomial fit and exponential fit, among others. The method of fitting is regression 


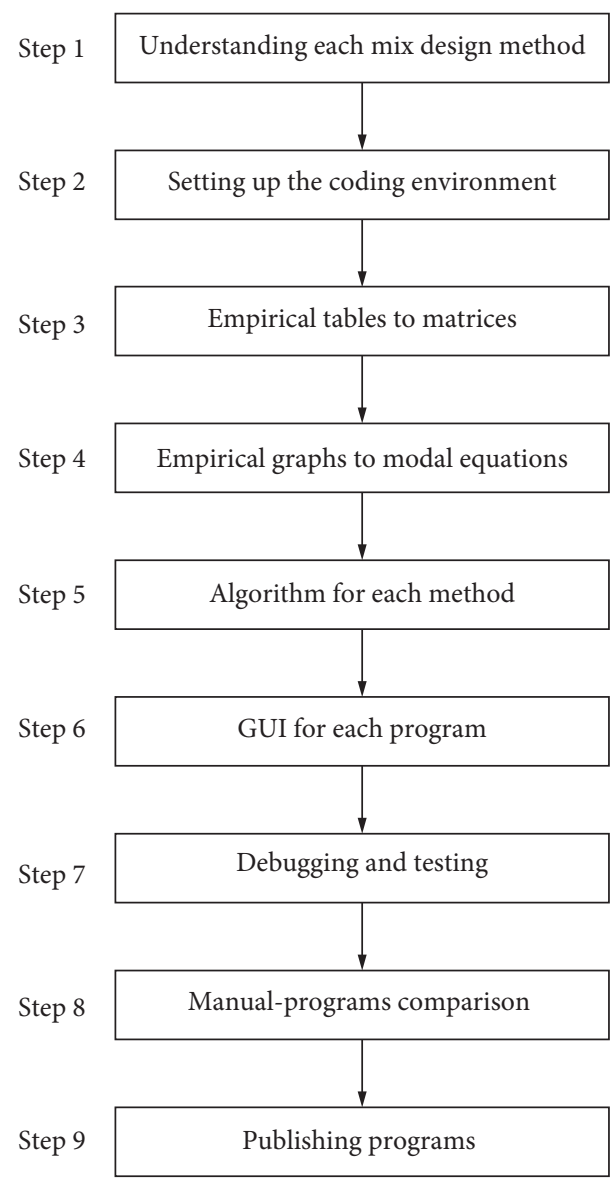

Figure 1: A block diagram describing the process of creating computer programs that replace manual calculations of a concrete mix design.

\begin{tabular}{|c|c|}
\hline $\begin{array}{l}\text { Probable compressive } \\
\text { strength at 28 days } f_{c}(\mathrm{MPa})\end{array}$ & $\begin{array}{c}\text { Water to cement } \\
\text { ratio }(w / c)\end{array}$ \\
\hline 45 & 0.38 \\
\hline 40 & 0.43 \\
\hline 35 & 0.48 \\
\hline 30 & 0.55 \\
\hline 25 & 0.62 \\
\hline 20 & 0.70 \\
\hline 15 & 0.80 \\
\hline
\end{tabular}

(a)

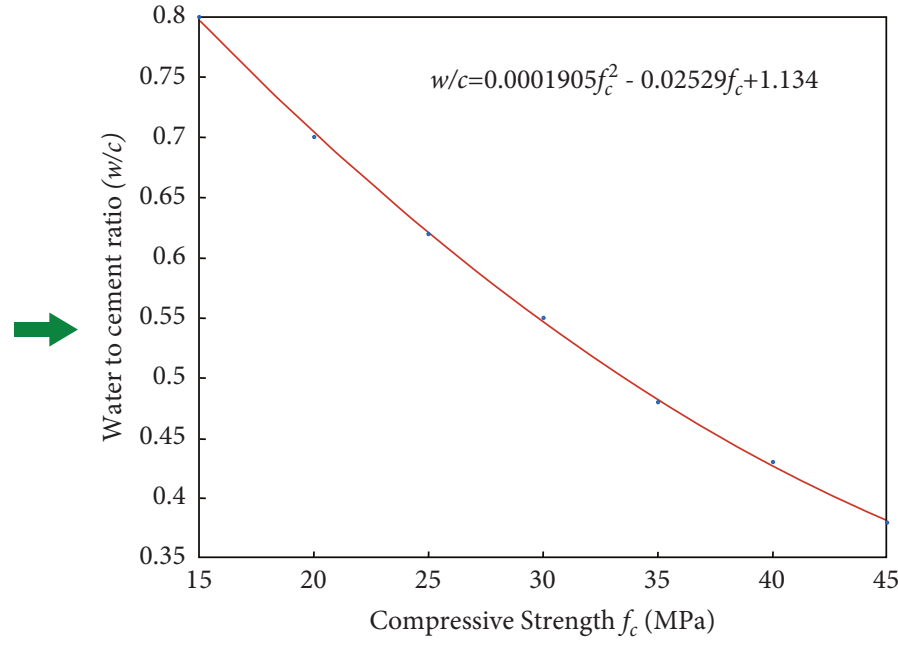

(b)

Figure 2: An example of converting tabular data into modal equations: (a) the table from the ACI method; (b) how tabular data were fitted with a $2^{\text {nd }}$ degree polynomial with an $R^{2}$ of 0.997 . 
methods [38]. All fit equations were polynomials of $R^{2}$ exceeding 0.99 (see Figure 2).

Step 4. Converting empirical graphs to modal equations. Graphs of the mix design methods were first converted from mere images to $\mathrm{x}$ - $\mathrm{y}$ graphs whose data points were later fitted and converted into their respective modal equations using the procedure outlined in Step 3. This was achieved by digitizing the curves by carefully tracing the curves in the source image and then converting them to $x-y$ data points. MathWorks-published tool GRABIT [39] was used for this job.

Step 5. Developing an algorithm for each method. An algorithm for each mix design method was created and programmed following the procedure reported in each method's source documents.

Step 6. Creating a GUI for each program. Each mix design method's program was converted into a GUIassisted program by using MATLAB's tool guide.

Step 7. Debugging and testing of the programs. A comprehensive checking and debugging of each program were conducted to ensure that programs run properly and error-free.

Step 8. Comparing programs to manual calculations. Ten comparisons between the output of the program and manual calculations were conducted for each of the six programs. In total, 60 comparisons were made between hand calculations and programs.

Step 9. Publishing the created programs. Upon testing of all programs, they were published as standalone programs using MATLAB's compiler for use by the community.

The programs take into consideration all the aspects of concrete mix design; for example, in the ACI method, the program considers the absorption and moisture content of aggregate and the different methods for calculation of sand content. Extra calculations are provided by the programs such as ingredients quantities for a specific casting quantity and the cost of the required concrete quantity in Saudi Riyals (SR). Ingredients costs were reported to us by local vendors at the date of writing this paper. It is worth mentioning that the range of values for each input is hinted to the user, and that if provided input data by the user is outside the limits, an error is shown. Additionally, default input values are pre-entered for the ease of use, such as cost of concrete constituents.

\subsection{Inputs and Output of Programs}

2.2.1. $A V M$. Input: the input is required strength, materials properties (w/c ratio, specific gravities, and bulk densities), cost of concrete constituents, casting quantity, and state of control on placing and mixing concrete.

Output: the output is weights (per cubic meter and per provided casting quantity) of cement, water, fine, and coarse aggregates and the associated cost. A flowchart of the program created in this work according to AVM is shown in Figure 3.
2.2.2. ACI 211. Input: the input is required strength, materials properties (specific gravities, bulk densities, and moisture content), maximum nominal size of coarse aggregates, required workability (slump value), cost of concrete constituents, casting quantity, and whether previous test records are available.

Output: the output is weights (per cubic meter and per provided casting quantity) of cement, water, fine, and coarse aggregates and the associated cost. A flowchart of the program created in this work according to ACI 211 is shown in Figure 3.

2.2.3. $D O E$. Input: the input is required strength, materials properties (specific gravities, bulk densities, and moisture content), maximum nominal size of coarse aggregates, types of coarse and fine aggregates, type of cement, exposure to harsh conditions, required workability (slump value), cost of concrete constituents, casting quantity, and whether previous test records are available.

Output: the output is weights (per cubic meter and per provided casting quantity) of cement, water, fine, and coarse aggregates, suggested ratios for coarse aggregates, and the associated cost. A flowchart of the program created in this work according to DOE is shown in Figure 3.

2.2.4. Aitcin. Input: the input is required strength, materials properties, properties of superplasticizer, aggregate shape, whether slag or/and silica fumes and/or fly ash are used, moisture content of fine and coarse aggregates, cost of concrete constituents, casting quantity, and whether previous test records are available.

Output: the output is weights (per cubic meter and per provided casting quantity) of cement, water, fine, and coarse aggregates as well as fly ash, silica fume, slag cement, superplasticizers, the calculated water/cement ratio, and the associated cost. A flowchart of the program created in this work according to Aitcin is shown in Figure 3.

2.2.5. Modified DOE. Input: the input is required strength, materials properties, maximum cement content, types of course and fine aggregates, type of cement, cost of concrete constituents, casting quantity, and whether previous test records are available.

Output: the output is weights (per cubic meter and per provided casting quantity) of cement, water, fine, and coarse aggregates as well as superplasticizers, suggested ratios for coarse aggregate, and the associated cost. A flowchart of the program created in this work according to modified DOE is shown in Figure 3.

2.2.6. ACI $211.4 R-8$. Input: the input is required strength, materials properties (specific gravities, bulk densities, and moisture content), maximum nominal size of coarse aggregates, required workability (slump), whether fly ash and/or admixtures are used, cost of concrete constituents, casting quantity, and whether previous test records are available. 


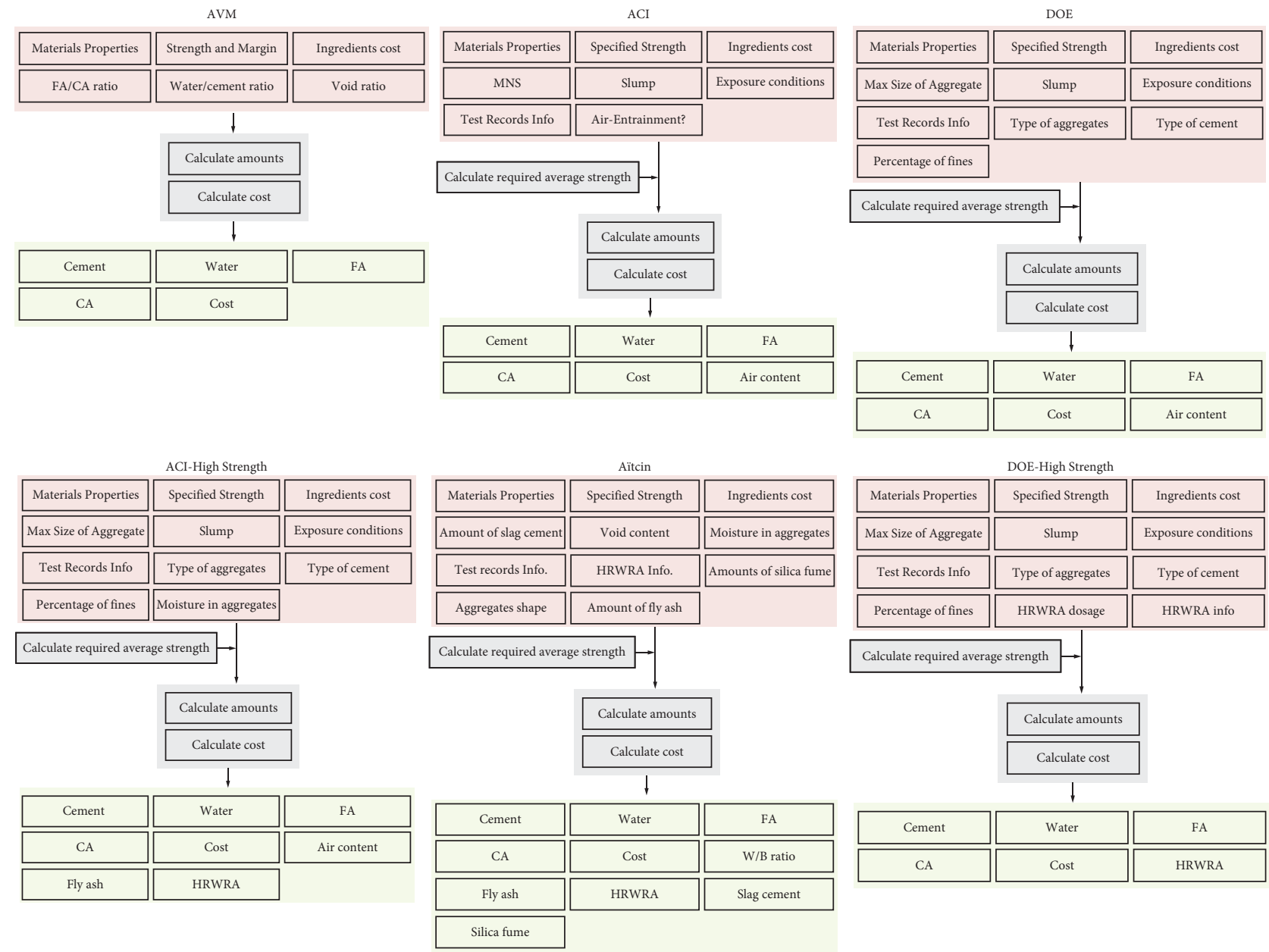

FIGURE 3: Flowcharts of the programs created in this work according to AVM, ACI, and DOE for normal strength and ACI Aïtcin and DOE for high strength mixes.

Output: the output is weights (per cubic meter and per provided casting quantity) of cement, water, fine, and coarse aggregates as well as fly ash and admixtures and the associated cost. A flowchart of the program created in this work according to ACI $211.4 \mathrm{R}-8$ is shown in Figure 3.

2.3. Comparisons of Mix Design Methods. Concrete mix design methods were compared in three main areas:

(i) Quantities of concrete constituents suggested by each method for the same required compressive strength

(ii) Cost associated with each design mix produced by each method for the same required compressive strength

(iii) General trends

\section{Results and Discussion}

3.1. Created Programs. A representative program of the created GUI-aided programs developed in this work is shown in Figure 4.
3.2. Example of Designing a Concrete Mix Using the Developed Programs. An example showcasing how data are inputted into the program and how results are shown is illustrated in Figure 5.

3.3. Manual vs. Program. The developed programs were compared with manual calculations for verification purposes. A total of 60 comparisons were made, and it was found that manual calculations and programs calculations agree very well. Representative comparisons are shown in Tables 3-7. Comparison between program and manual calculations for AVM is not shown here as values calculated by the program are identical to those calculated by hand.

\subsection{Comparisons between Mix Design Methods}

3.4.1. Normal Strength. The three methods for designing normal strength mixes suggest comparable constituents' quantities when designed for a 28-day strength of $30 \mathrm{MPa}$ and MNS of $10 \mathrm{~mm}$ (Figure 6(a)). However, when the used aggregates are uncrushed, the DOE method suggests higher quantities of coarse aggregates and fine aggregates than the 


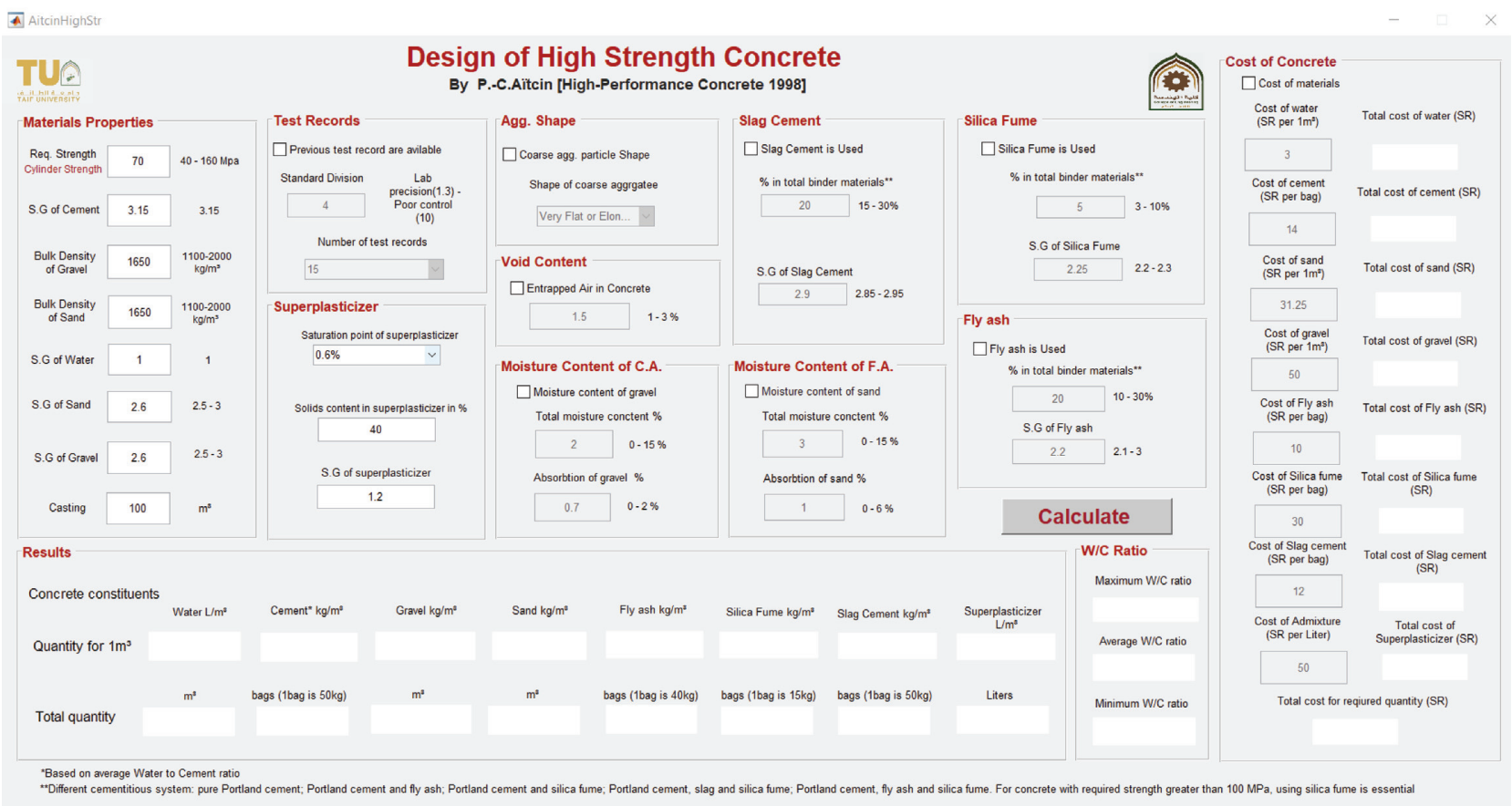

FIGURE 4: The Aïtcin high strength mix design method programs shown here as a representative program of the six mix design programs.

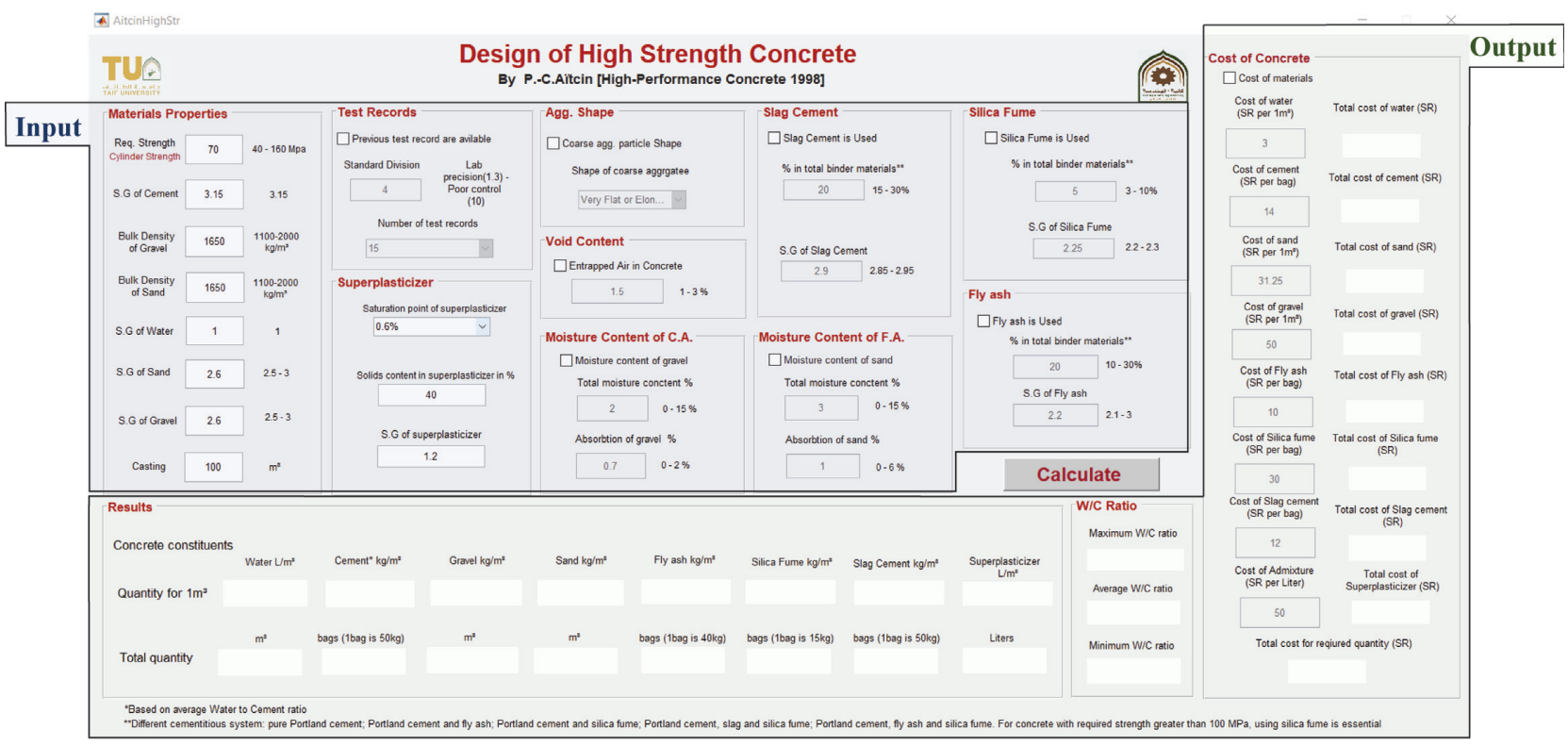

Figure 5: An example showcasing how data are inputted into the program and how results are shown to the user.

TABLE 3: Comparison between manual and program results for the ACI 211 method.

\begin{tabular}{|c|c|c|c|c|}
\hline \multirow{2}{*}{ Mix proportions } & \multirow{2}{*}{ Manual } & \multirow{2}{*}{ Program } & \multicolumn{2}{|c|}{ Variation } \\
\hline & & & Numeric & $\%$ \\
\hline Cement $\left(\mathrm{kg} / \mathrm{m}^{3}\right)$ & 390 & 390 & 0 & 0 \\
\hline Water $\left(\mathrm{kg} / \mathrm{m}^{3}\right)$ & 195 & 195 & 0 & 0 \\
\hline FA $\left(\mathrm{kg} / \mathrm{m}^{3}\right)$ & 726 & 728.99 & -2.99 & -0.41 \\
\hline $\mathrm{CA}\left(\mathrm{kg} / \mathrm{m}^{3}\right)$ & 1089 & 1078.8 & 10.2 & 0.94 \\
\hline
\end{tabular}


TABLE 4: Comparison between manual and program results for the DOE method.

\begin{tabular}{|c|c|c|c|c|}
\hline \multirow{2}{*}{ Mix proportions } & \multirow{2}{*}{ Manual } & \multirow{2}{*}{ Program } & \multicolumn{2}{|c|}{ Variation } \\
\hline & & & Numeric & $\%$ \\
\hline Cement $\left(\mathrm{kg} / \mathrm{m}^{3}\right)$ & 371.681 & 371.89 & -0.21 & -0.06 \\
\hline Water $\left(\mathrm{kg} / \mathrm{m}^{3}\right)$ & 210 & 210 & 0 & 0 \\
\hline FA $\left(\mathrm{kg} / \mathrm{m}^{3}\right)$ & 566.823 & 565.88 & 0.94 & 0.17 \\
\hline $\mathrm{CA}\left(\mathrm{kg} / \mathrm{m}^{3}\right)$ & 1193.496 & 1193.73 & -0.23 & -0.02 \\
\hline
\end{tabular}

TABLE 5: Comparison between manual and program results for the Aïtcin method.

\begin{tabular}{|c|c|c|c|c|}
\hline \multirow{2}{*}{ Mix proportions } & \multirow{2}{*}{ Manual } & \multirow{2}{*}{ Program } & \multicolumn{2}{|c|}{ Variation } \\
\hline & & & Numeric & $\%$ \\
\hline Cement $\left(\mathrm{kg} / \mathrm{m}^{3}\right)$ & 439.015 & 442 & -2.99 & -0.68 \\
\hline Water $\left(\mathrm{kg} / \mathrm{m}^{3}\right)$ & 118.114 & 117.98 & 0.13 & 0.11 \\
\hline FA $\left(\mathrm{kg} / \mathrm{m}^{3}\right)$ & 654.836 & 658.61 & -3.77 & -0.58 \\
\hline $\mathrm{CA}\left(\mathrm{kg} / \mathrm{m}^{3}\right)$ & 1089 & 1089 & 0 & 0 \\
\hline Silica fume $\left(\mathrm{kg} / \mathrm{m}^{3}\right)$ & 25.824 & 26 & -0.18 & -0.68 \\
\hline Fly ash $\left(\mathrm{kg} / \mathrm{m}^{3}\right)$ & 51.649 & 52 & -0.35 & -0.68 \\
\hline Superplasticizer $\left(\mathrm{kg} / \mathrm{m}^{3}\right)$ & 7.65 & 7.7 & -0.05 & -0.65 \\
\hline
\end{tabular}

TABLE 6: Comparison between manual and program results for the modified DOE method.

\begin{tabular}{|c|c|c|c|c|}
\hline \multirow{2}{*}{ Mix proportions } & \multirow{2}{*}{ Manual } & \multirow{2}{*}{ Program } & \multicolumn{2}{|c|}{ Variation } \\
\hline & & & Numeric & $\%$ \\
\hline Cement $\left(\mathrm{kg} / \mathrm{m}^{3}\right)$ & 617.28 & 614.49 & 2.79 & 0.45 \\
\hline Water $\left(\mathrm{kg} / \mathrm{m}^{3}\right)$ & 170.26 & 170.31 & -0.05 & -0.03 \\
\hline FA $\left(\mathrm{kg} / \mathrm{m}^{3}\right)$ & 518.66 & 517.61 & 1.05 & 0.2 \\
\hline $\mathrm{CA}\left(\mathrm{kg} / \mathrm{m}^{3}\right)$ & 1098.54 & 1106.28 & -7.74 & -0.7 \\
\hline Superplasticizer $\left(\mathrm{kg} / \mathrm{m}^{3}\right)$ & 6.688 & 6.66 & 0.03 & 0.42 \\
\hline
\end{tabular}

TABLE 7: Comparison between manual and program results for the ACI 211.4R-8 method.

\begin{tabular}{|c|c|c|c|c|}
\hline \multirow{2}{*}{ Mix proportions } & \multirow{2}{*}{ Manual } & \multirow{2}{*}{ Program } & \multicolumn{2}{|c|}{ Variation } \\
\hline & & & Numeric & $\%$ \\
\hline Cement $\left(\mathrm{kg} / \mathrm{m}^{3}\right)$ & 334.8 & 337.94 & -3.14 & -0.93 \\
\hline Water $\left(\mathrm{kg} / \mathrm{m}^{3}\right)$ & 188.92 & 188.89 & 0.03 & 0.02 \\
\hline $\mathrm{FA}\left(\mathrm{kg} / \mathrm{m}^{3}\right)$ & 613.4 & 610.09 & 3.31 & 0.54 \\
\hline $\mathrm{CA}\left(\mathrm{kg} / \mathrm{m}^{3}\right)$ & 1072.5 & 1072.5 & 0 & 0.00 \\
\hline Fly ash $\left(\mathrm{kg} / \mathrm{m}^{3}\right)$ & 63.77 & 64.37 & -0.6 & -0.93 \\
\hline Superplasticizer $\left(\mathrm{kg} / \mathrm{m}^{3}\right)$ & 2.39 & 2.41 & -0.02 & -0.83 \\
\hline
\end{tabular}

other methods. The amount of cement calculated by the ACI method is higher than that calculated from the other methods. It is also worth mentioning that the difference between quantities of materials using the ACI method is very similar for both air-entrained and non air-entrained, however, with higher air content in the mix designed by the former.

By comparing the mixes designed by the three methods when the strength is increased to $40 \mathrm{MPa}$ and $40 \mathrm{~mm}$ MNS is used, we observe that the AVM suggests lowering the amount of coarse aggregates by $14 \%$, roughly, while both ACI and DOE suggest increasing the amount of CA by approximately $50 \%$. In addition, when the used coarse aggregates are uncrushed, the DOE method reduces the amount of fine aggregates by approximately half (see Figure 6(b)).

In Figure 7(a), it can be seen that when comparing the cost associated with designing a concrete mix for a 28-day strength of $30 \mathrm{MPa}$ using AVM, DOE, and ACI and varying MNS, type of aggregates, and for air-entrainment and non air-entrainment, we notice that the AVM method provides the cheapest mix while DOE and ACI provide mixes with comparable costs. The reason behind AVM costing less than ACI and DOE is that it suggests low amounts of cement (see Figure $6(\mathrm{a})$ ). When the strength is increased by $5 \mathrm{MPa}$, the cost trend becomes more evident as the ACI suggests mixes that cost more than the other methods (see Figure 7(b)).

As cement is the main influencers on cost, in Figure 8, we compare the cement content calculated by the three methods for normal strength mixes as the 28-day compressive strength increases from 20 to $40 \mathrm{MPa}$, with varying MNS and when the required slump is $50 \mathrm{~mm}$ (Figure $8(\mathrm{a})$ ) and $100 \mathrm{~mm}$ (Figure 8(b)). In both cases, $50 \mathrm{~mm}$ and $100 \mathrm{~mm}$ concrete consistency requirements, and for all MNS, it is clear that in most of the cases, ACI suggests higher amounts of cement as strength increases than other methods. It is important to 


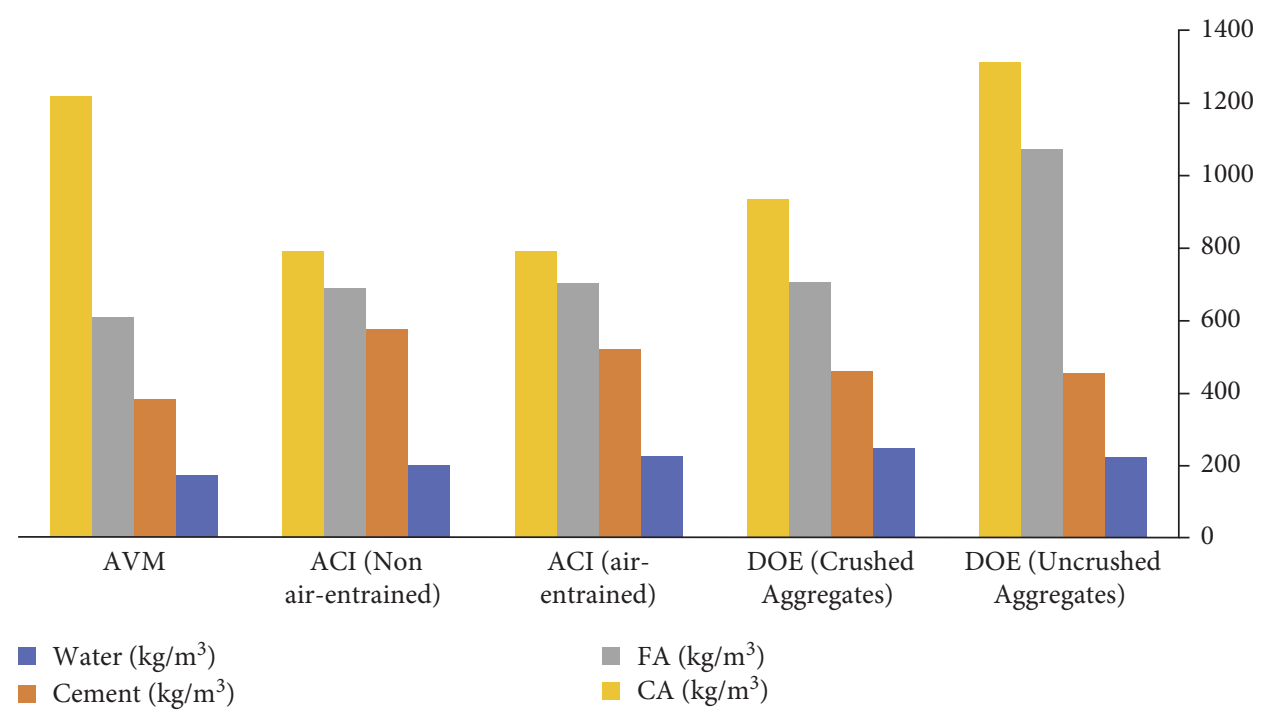

(a)

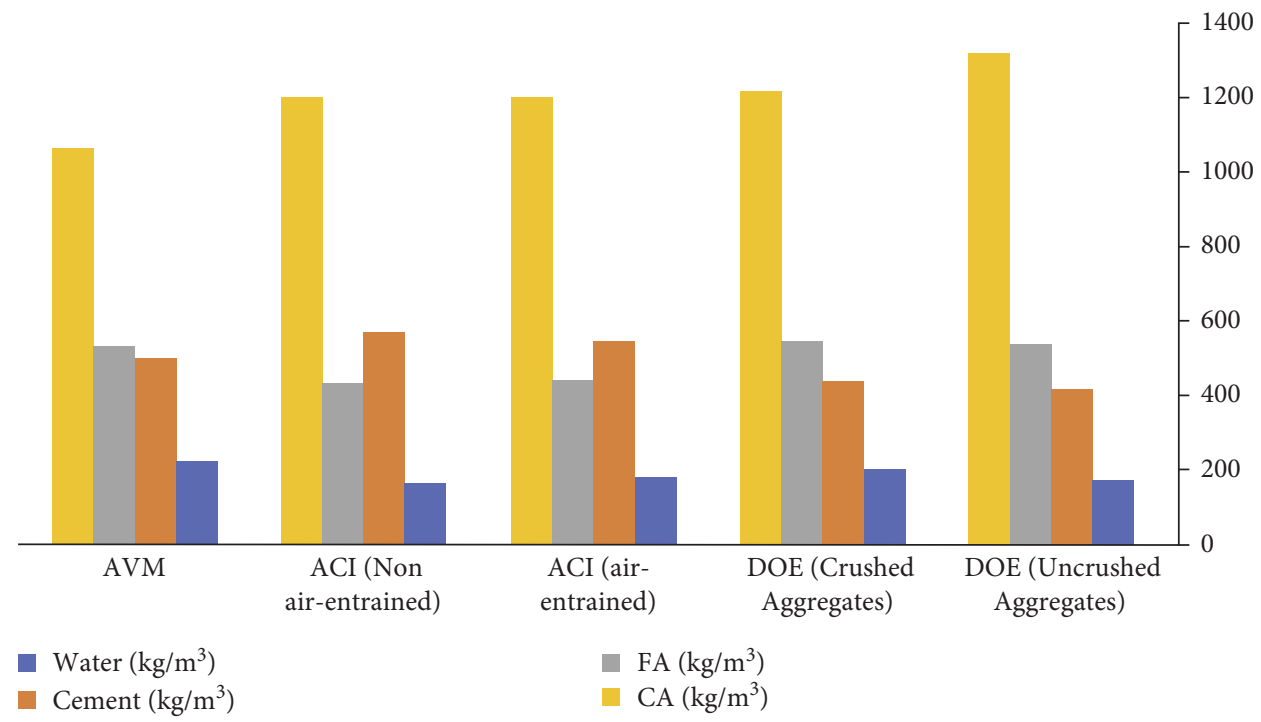

(b)

FIGURE 6: Comparison of material quantities for normal strength design methods for (a) $30 \mathrm{MPa}$ and MNS $10 \mathrm{~mm}$ and (b) $40 \mathrm{MPa}$ and MNS $40 \mathrm{~mm}$.

note that while ACI mixes cost more, experimentally, they are found to be more cost effective and efficient than DOE $[18,31]$.

3.4.2. High Strength Concrete. In the comparison between the high strength methods, namely, the modified DOE, the ACI, and the Aitcin method, we can see that methods provide similar estimates of the quantities of water, cement, aggregates, and HRWRA (superplasticizer) for 60 and $70 \mathrm{MPa}$ 28-day compressive strengths (see Figure 9). However, the mixes designed by the high strength ACI method cost more than those designed by modified DOE and Aïtcin methods (see Figure 10). This trend becomes clearer when we compare the cement content suggested by each of the three methods as the 28-day strength increases from $60 \mathrm{MPa}$ to $80 \mathrm{MPa}$ (see Figure 11). It should be noted that when these comparisons were made, only superplasticizers were used in the mixes as an admixture.

\section{Limitations of This Study}

Every mix design method suggests conducting trail mixes and testing the resulting hardened concrete samples to ensure that the designed mix can produce the required compressive strength. A comprehensive comparison of mix design methods would require comparing other parameters such as the cost of a concrete mix normalized by its experimentally found strength. While this study provides engineers and scholars with tools to easily design and compare normal and high strength mixes, it is vital that results presented in this work are compared with results of experimental tests; therefore, it is the intent of the authors to 
(a)

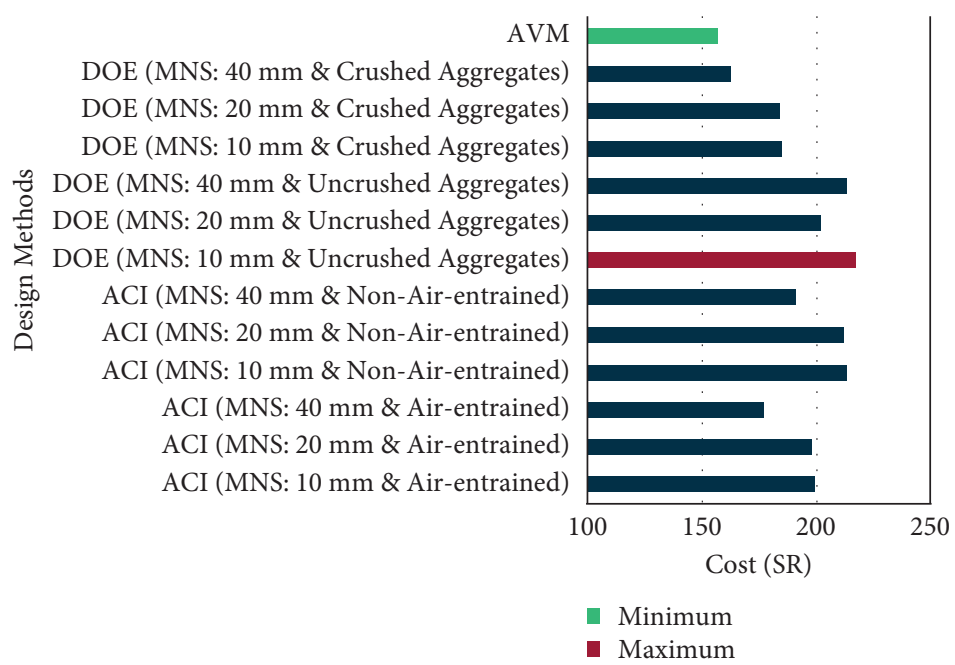

(b)

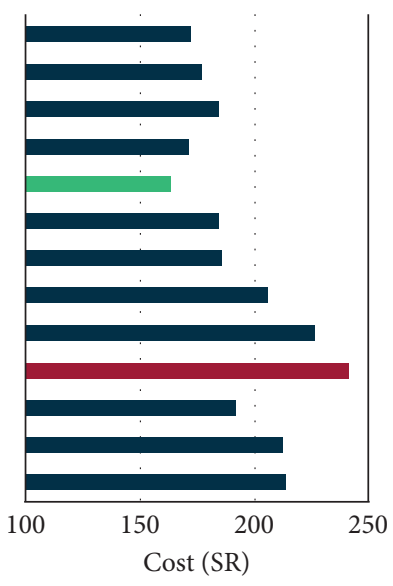

Minimum

- Maximum

FIgURE 7: Cost comparison between normal strength design methods for a 28-day strength of (a) $30 \mathrm{MPa}$ and (b) $35 \mathrm{MPa}$.

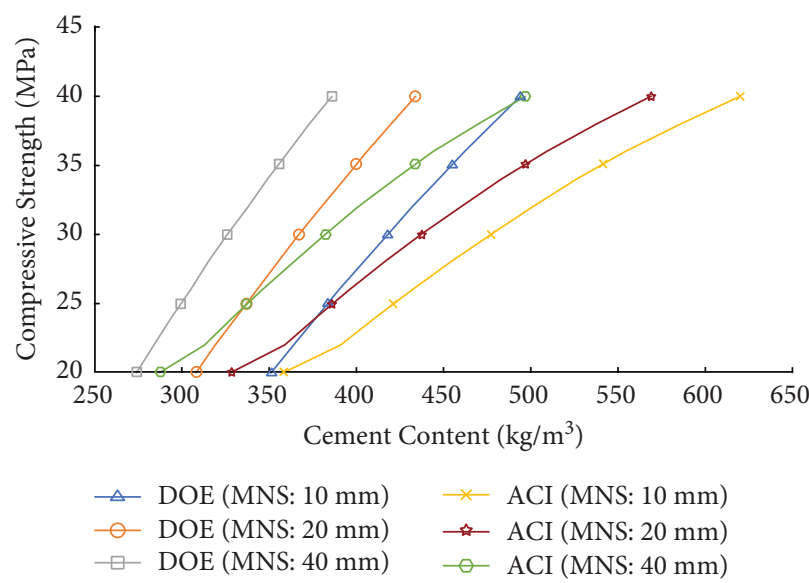

(a)

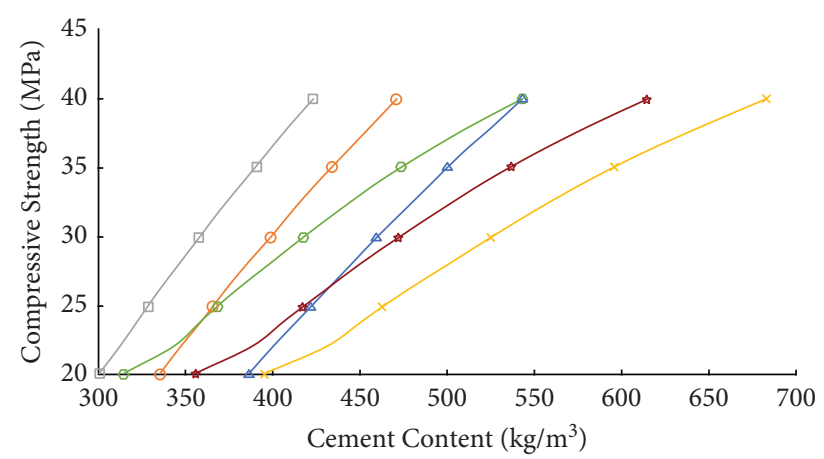

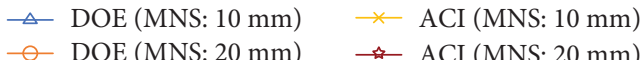

$\square$ DOE (MNS: $40 \mathrm{~mm}$ ) $\rightarrow$ ACI (MNS: $40 \mathrm{~mm}$ )

(b)

FIGURE 8: Comparison between normal strength design methods for varying MNS for (a) $50 \mathrm{~mm}$ slump and (b) $100 \mathrm{~mm}$ slump.

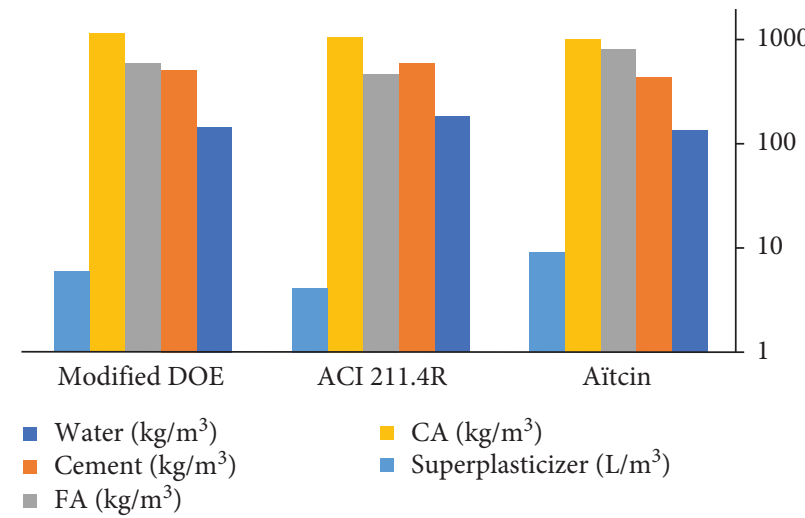

(a)

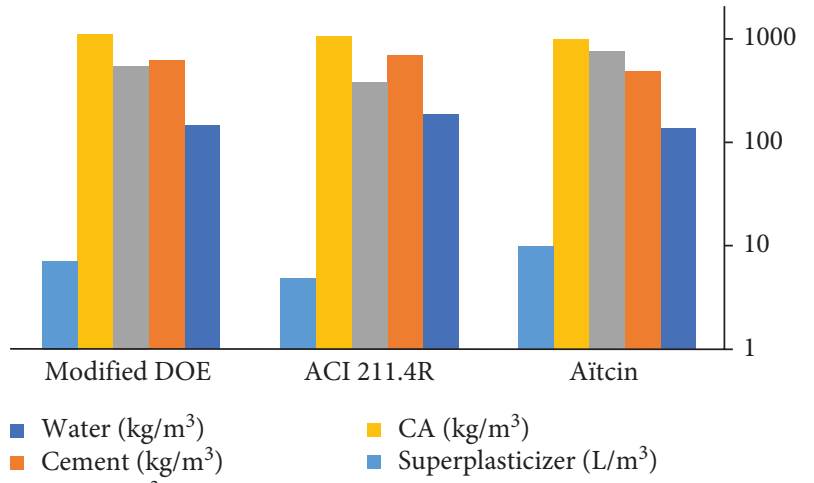

(b)

FIgURE 9: Comparison of material quantities for high strength design methods for a 28-day strength of (a) $60 \mathrm{MPa}$ and (b) $70 \mathrm{MPa}$. 


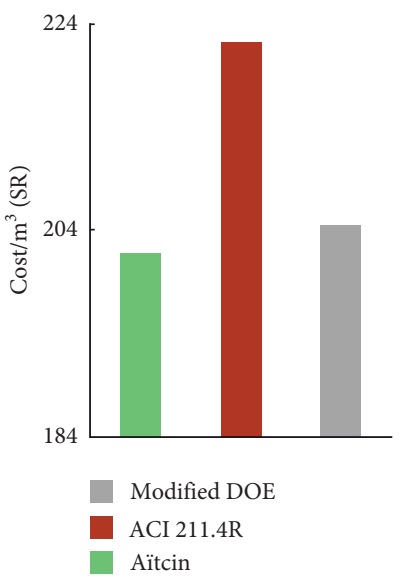

(a)

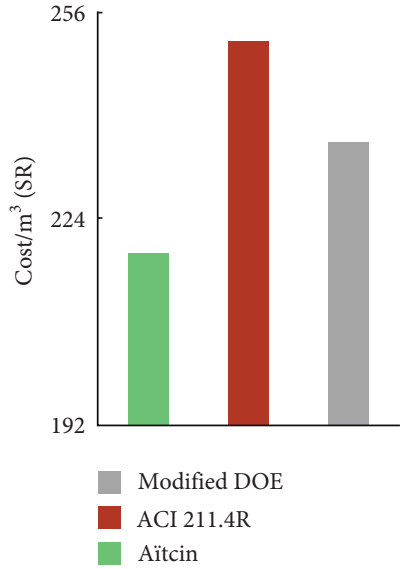

(b)

FIGURE 10: Cost comparison between different design high strength design methods for a 28-day strength of (a) $60 \mathrm{MPa}$ and (b) $70 \mathrm{MPa}$.

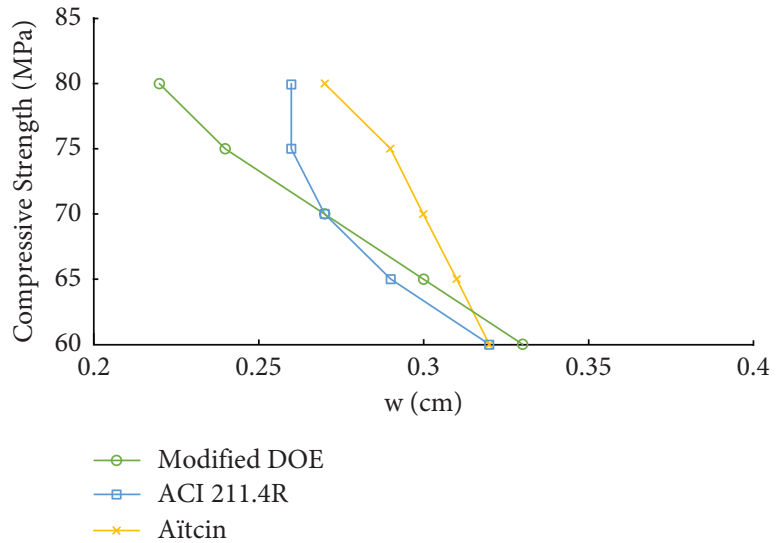

(a)

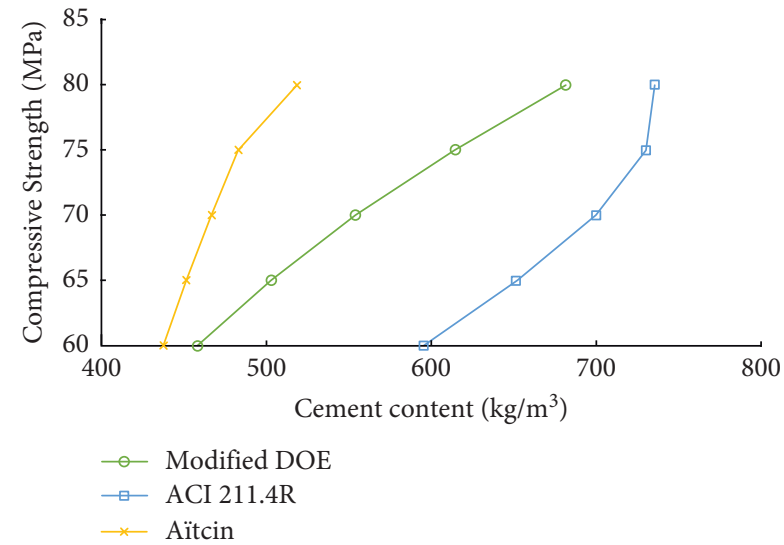

(b)

Figure 11: Comparison of high strength design methods with respect to (a) w/cm and (b) cement content.

perform experimental studies to complement the results presented herein. In addition, this work does not include any of the particle packing methods as it is focused on the widely used basic methods of mix design.

\section{Conclusions}

In this work, we developed and implemented MATLAB GUI-assisted programs that are capable of designing concrete mixes of both normal and high strengths. The developed programs were used to design concrete mixes of normal strength and high strength mixes ranging from 10 to $160 \mathrm{MPa} 28$-day compressive strengths. Calculations from the developed programs were compared with manual calculations for verification purposes, and results from manual calculations and programs agree very well. More importantly, comparisons among mix design methods were easily made via the created programs. In the case of normal strength concrete, the ACI 211 method suggests higher amounts of cement than both Absolute Volume method and Department of Environment method. Comparisons between the high strength methods show that the three compared methods provide similar estimates of the quantities of water, cement, aggregates, and superplasticizer for different 28-day compressive strengths and that the mixes designed by the high strength ACI method cost more than those designed by modified DOE and Aitcin methods. The comparisons presented in this work are only a few of the unlimited comparisons that can be easily made between normal and high strength mix design methods. Such comparisons are vital to engineers to be able to make informed decisions regarding which mix to use from strength, workability, durability, and cost point of views. The published programs from this work will be of great help to engineers and researchers working in the field of construction and concrete manufacturing as they make the process of designing and comparing concrete mixes very easily performed with error-free fast calculations. Additionally, this work emphasizes the necessity and the effectiveness of using simple programs to solve fundamental civil engineering problems. Future work shall extend the current to include experimental validation and computer simulation. 


\section{Data Availability}

All data, models, or codes that support the findings of this study are available from the corresponding author upon reasonable request.

\section{Conflicts of Interest}

The authors declare that they have no conflicts of interest.

\section{Authors' Contributions}

Alghamdi, Alsaluli, Alwetaishi, and Alsehli conceptualized the idea and methodology. Abdul Qader, Ibrahim, Al Aidaros, Abdulkareem, and Alwuayl created and tested the programs. All authors discussed the results and wrote the manuscript.

\section{Acknowledgments}

This research was funded by Taif University Researchers Supporting Project (number TURSP-2020/204), Taif University, Taif, Saudi Arabia.

\section{References}

[1] A. R. Mankenya and P. M. John, "Potentiality of using a developed MATLAB program for the design of high strength concrete mixes," Journal of Civil Engineering Research, vol. 7, pp. 81-98, 2017.

[2] T. N. Ganju, "Spreadsheeting mix designs," Concrete International, vol. 18, no. 12, pp. 35-38, 1996.

[3] J. Kasperkiewicz, "Optimization of concrete mix using a spreadsheet package," Materials Journal, vol. 91, no. 6, pp. 551-559, 1995.

[4] T. S. Teo and M. Tan, "Quantitative and qualitative errors in spreadsheet development," vol. 3, pp. 149-155, in Proceedings of the Thirtieth Hawaii International Conference on System Sciences, vol. 3, IEEE, Wailea, HI, USA, January 1997.

[5] P. S. Brown and J. D. Gould, "An experimental study of people creating spreadsheets," ACM Transactions on Information Systems, vol. 5, no. 3, pp. 258-272, 1987.

[6] R. R. Panko and R. P. Halverson, "Spreadsheets on trial: a survey of research on spreadsheet risks,"vol. 2, pp. 326-335, in Proceedings of the HICSS-29: 29th Hawaii International Conference on System Sciences, vol. 2, pp. 326-335, IEEE, Wailea, HI, USA, January 1996.

[7] IBM, The Risks of Using Spreadsheets for Statistical Analysis, IBM Software Business Analytics, Armonk, NY, USA, 2010.

[8] D. Zealakshmi, A. Ravichandran, and S. Kothandaraman, "Computer aided high strength concrete mixture proportion using mat," Lab. International Journal of Computer Applications, vol. 70, no. 8, 2013.

[9] H. C. Erntroy and B. W. Shacklock, "Design of high-strength concrete mixes," in Proceedings of the Symposium of Mix Design and Quality Control of Concrete, pp. 55-75, Cement and Concrete Association, London, UK, May 1954.

[10] M. Abdullahi, H. M. Al-Mattarneh, B. S. Mohammed, and S. Sadiku, "M-file for mix design of structural lightweight concrete using developed models," Journal of Engineering Science \& Technology, vol. 6, no. 4, pp. 520-531, 2011.
[11] W. J. L. X. L. Binqiao and J. Lijun, "Mix optimization design OF high-performance concrete based ON M atlab," Industrial Construction, vol. 1, 2005.

[12] I.-C. Yeh, "Modeling of strength of high-performance concrete using artificial neural networks," Cement and Concrete Research, vol. 28, no. 12, pp. 1797-1808, 1998.

[13] S.-C. Lee, "Prediction of concrete strength using artificial neural networks," Engineering Structures, vol. 25, no. 7, pp. 849-857, 2003.

[14] R. Gupta, M. A. Kewalramani, and A. Goel, "Prediction of concrete strength using neural-expert system," Journal of Materials in Civil Engineering, vol. 18, no. 3, pp. 462-466, 2006.

[15] F. Khademi, M. Akbari, S. M. Jamal, and M. Nikoo, "Multiple linear regression, artificial neural network, and fuzzy logic prediction of 28 days compressive strength of concrete," Frontiers of Structural and Civil Engineering, vol. 11, no. 1, pp. 90-99, 2017.

[16] D.-K. Bui, T. Nguyen, J.-S. Chou, H. Nguyen-Xuan, and T. D. Ngo, "A modified firefly algorithm-artificial neural network expert system for predicting compressive and tensile strength of high-performance concrete," Construction and Building Materials, vol. 180, pp. 320-333, 2018.

[17] F. Deng, Y. He, S. Zhou, Y. Yu, H. Cheng, and X. Wu, "Compressive strength prediction of recycled concrete based on deep learning," Construction and Building Materials, vol. 175, pp. 562-569, 2018.

[18] A. Santoso, "Analysis OF mix design beton HOW DOE (English) and ACI (America)," Jurnal Penelitian Saintek, vol. 7, no. 1, 2002.

[19] J. Kasperkiewicz, J. Racz, and A. Dubrawski, "HPC strength prediction using artificial neural network," Journal of Computing in Civil Engineering, vol. 9, no. 4, pp. 279-284, 1995.

[20] W. P. S. Dias and S. P. Pooliyadda, "Neural networks for predicting properties of concretes with admixtures," Construction and Building Materials, vol. 15, no. 7, pp. 371-379, 2001.

[21] A. Öztaş, M. Pala, E. Özbay, E. Kanca, N. Caglar, and M. A. Bhatti, "Predicting the compressive strength and slump of high strength concrete using neural network," Construction and Building Materials, vol. 20, no. 9, pp. 769-775, 2006.

[22] E. Ghafari, M. Bandarabadi, H. Costa, and E. Júlio, "Prediction of fresh and hardened state properties of UHPC: comparative study of statistical mixture design and an artificial neural network model," Journal of Materials in Civil Engineering, vol. 27, no. 11, Article ID 4015017, 2015.

[23] İ. B. Topçu and M. Sarıdemir, "Prediction of properties of waste AAC aggregate concrete using artificial neural network," Computational Materials Science, vol. 41, no. 1, pp. 117-125, 2007.

[24] M. M. Alshihri, A. M. Azmy, and M. S. El-Bisy, "Neural networks for predicting compressive strength of structural light weight concrete," Construction and Building Materials, vol. 23, no. 6, pp. 2214-2219, 2009.

[25] R. Siddique, P. Aggarwal, and Y. Aggarwal, "Prediction of compressive strength of self-compacting concrete containing bottom ash using artificial neural networks," Advances in Engineering Software, vol. 42, no. 10, pp. 780-786, 2011.

[26] J.-S. Chou, C.-K. Chiu, M. Farfoura, and I. Al-Taharwa, "Optimizing the prediction accuracy of concrete compressive strength based on a comparison of data-mining techniques," Journal of Computing in Civil Engineering, vol. 25, no. 3, pp. 242-253, 2011.

[27] H. I. Erdal, "Two-level and hybrid ensembles of decision trees for high performance concrete compressive strength 
prediction," Engineering Applications of Artificial Intelligence, vol. 26, no. 7, pp. 1689-1697, 2013.

[28] I. Mansouri, T. Ozbakkaloglu, O. Kisi, and T. Xie, "Predicting behavior of FRP-confined concrete using neuro fuzzy, neural network, multivariate adaptive regression splines and M5 model tree techniques," Materials and Structures, vol. 49, no. 10, pp. 4319-4334, 2016.

[29] N. Deshpande, S. Londhe, and S. Kulkarni, "Modeling compressive strength of recycled aggregate concrete by artificial neural network, model tree and non-linear regression," International Journal of Sustainable Built Environment, vol. 3, no. 2, pp. 187-198, 2014.

[30] C. Deepa, K. SathiyaKumari, and V. P. Sudha, "Prediction of the compressive strength of high performance concrete mix using tree based modeling," International Journal of Computer Application, vol. 6, no. 5, pp. 18-24, 2010.

[31] I. K. Ejiogu, P. A. Mamza, P. O. Nkeonye, and S. A. Yaro, "Comparison of aci, is and doe methods of concrete mix design," Nigerian Journal Of Engineering, vol. 27, no. 1, pp. 68-83, 2020.

[32] D. E. Dixon, J. R. Prestrera, G. R. Burg et al., Standard Practice for Selecting Proportions for Normal, Heavyweight, and Mass Concrete, 1991.

[33] D. C. Teychenné, R. E. Franklin, H. C. Erntroy, and B. K. Marsh, Design of Normal Concrete Mixes, HM Stationery Office, London, UK, 1975.

[34] L. Zongjin, Advanced Concrete Technology, John Wiley \& Sons, Hoboken, NJ, USA, 2011.

[35] O. Alonzo, W. L. Barringer, S. G. Barton et al., "Guide for selecting proportions for high-strength concrete with portland cement and fly ash," ACI Materials Journal, vol. 90, no. 3, pp. 272-283, 1993.

[36] P. C. Aitcin, High Performance Concrete, CRC Press, Boca Raton, FL, USA, 1998.

[37] S. Y. N. Chan, M. K. C. Tsang, and J. K. W. Chan, "A systematic mix design method for high strength concrete," HKIE Transactions, vol. 3, no. 2, pp. 1-6, 1996.

[38] S. C. Chapra, Applied Numerical Methods with MATLAB for Engineers and Scientists, McGraw-Hill Higher Education, Newyork, NY, USA, 2008.

[39] Jiro: 2022, GRABIT https://www.mathworks.com/matlab central/fileexchange/7173-grabit, MATLAB Central File Exchange. 